\title{
SEGURO DE DEPÓSITOS EN EL SISTEMA FINANCIERO PERUANO
}

\author{
DEPOSIT INSURANCE IN THE PERUVIAN FINANCIAL SYSTEM \\ Vladimir RodríGuez CAIRo* \\ Docente Asociado de la Facultad de Ciencias Contables \\ Universidad Nacional Mayor de San Marcos-UNMSM / Lima-Perú \\ [Recepción: Marzo de 2015/ Conformidad: Abril 2015]
}

\section{RESUMEN}

El presente estudio explica la importancia de crear un seguro de depósitos en el sistema financiero para evitar retiradas masivas del capital de un banco y sobre esa base, busca responder la siguiente interrogante: ¿Por qué es relevante para el sistema financiero la cobertura de los depósitos de ahorro a través de un seguro? En ese sentido, cabe precisar que la naturaleza del estudio es de tipo explicativo y los métodos de investigación utilizados son el analítico e inductivo. Asimismo, se ha recurrido a fuentes de información secundarias y la técnica usada ha sido la revisión documental.

Desde tal perspectiva, para una mejor comprensión del tema propuesto, el contenido se ha estructurado en tres partes: La primera comprende la fundamentación microeconómica del seguro de depósitos en el sistema financiero; en la segunda se plantea la importancia y protección del ahorro y la tercera abarca el Fondo de Seguro de Depósitos en el Perú. Finalmente, se presentan las conclusiones y se da a conocer la bibliografía.

Palabras clave:

Seguro de depósitos; protección; sistema financiero; Perú.

\begin{abstract}
This study explains the importance of creating deposit insurance in the financial system to prevent massive withdrawals of bank capital; and on that basis, seeks to answer the question: Why is it important for the financial system to have coverage for saving deposits through insurance?

In that regard, it should be noted that the nature of the study is explanatory type and the research methods used are analytic and inductive. Furthermore, we used secondary information sources and the technique used was documentary examination.

From this perspective, for a better understanding of the proposed theme, content is structured in three parts: The first includes the microeconomic foundations of deposit insurance in the financial system, the second states the importance and protection of savings and the third covers the Deposit Insurance Fund in Peru. Finally, conclusions are presented and the references are disclosed.
\end{abstract}

\section{Keywords:}

Deposit Insurance; protection; financial system; Peru.

* Doctor en Derecho y Ciencia Política y Magíster en Finanzas - UNMSM. Email: vladirodriguezcairo@yahoo.es 


\section{INTRODUCCIÓN}

El seguro de depósitos es una solución al riesgo moral que existe en el sistema financiero ante una situación de pánico bancario, ya que constituye una garantía de que los depositantes recibirán su dinero, ante la eventual situación que el banco quiebre. Para tal efecto, se establece un monto máximo de cobertura, respaldando de esta manera, los depósitos nominativos bajo cualquier modalidad, tanto de personas naturales como jurídicas privadas sin fines de lucro; así como, los depósitos a la vista de las demás personas jurídicas.

En estricto, nuestro país similar a otros, optó crear en 1991, el seguro de depósitos bajo la denominación de Fondo de Seguro de Depósitos (FSD), que viene a ser una persona jurídica de derecho privado, que tiene por objeto proteger a quienes realicen depósitos o imposiciones en las empresas del sistema financiero. No obstante, la cobertura tiene lugar por persona en cada empresa miembro del fondo. De ahí que, si una persona tiene depósitos de ahorro en más de una empresa miembro del FSD, estos se encuentran asegurados en cada una de ellas hasta por el monto máximo de cobertura.

Dentro de este contexto, el objetivo del estudio consiste en explicar por qué es relevante la cobertura de los depósitos de ahorro a través de un seguro. Se analiza un caso sencillo de un banco con solo dos depositantes, donde el mejor equilibrio se da cuando ambos deciden dejar su dinero en el banco. Esta situación es el efecto retención originado por el seguro de depósitos, que a su vez, beneficia al sistema financiero en su conjunto (externalidad positiva).

\section{FUNDAMENTACIÓN MICROECONÓMICA DEL SEGURO DE DEPÓSITOS EN EL SISTEMA FINANCIERO}

Previamente a la explicación de los fundamentos microeconómicos del seguro de depósitos, cabe precisar, que los depósitos en el sistema financiero ${ }^{1}$ son los fondos confiados por un depositante a una empresa del sistema financiero, en el que dicha empresa tiene el derecho a disponer de los mismos y a su vez, se encuentra obligado en atender el requerimiento del depositante, en caso éste lo solicite.

Ahora bien, el pánico bancario se refiere a la situación en la que todos los depositantes de un banco tratan de retirar su dinero al mismo tiempo, y debido a ello, el banco se ve forzado a vender sus activos a precios bajos, lo que finalmente termina causando la quiebra de tales entidades e inclusive, a los depositantes que no entraron en pánico les puede ir peor ${ }^{2}$.

Para Jean Tirole ${ }^{3}$ como los hogares pueden no tener información suficiente para evaluar y supervisar el estado de los bancos donde guardan sus depósitos, los consumidores pueden sufrir consecuencias graves en caso de fallo de una institución financiera. Esta falta de información también puede desencadenar pánicos financieros, donde muchos individuos "corren" para retirar sus depósitos de un banco que se rumorea que está fallando (incluso si el rumor resulta ser falso), con eficacia haciendo después que el banco fracase.

Como exponen Krugman y Wells (2014: 420) históricamente, ha quedado demostrado que (el pánico bancario) suele ser contagioso, ya que tras una retirada masiva del capital de un banco se pierde la fe en los demás bancos, provocando retiradas masivas adicionales. Los autores añaden ${ }^{4}$ que como prevención de tales sucesos, a partir de 1930 los Estados

1 El sistema financiero es el conjunto de empresas, que debidamente autorizadas operan en la intermediación financiera (captación y colocación de fondos). Incluye las subsidiarias que requieran de autorización de la Superintendencia para constituirse. En: Glosario de la Ley No 26702, Ley General del Sistema Financiero y del Sistema de Seguros y Orgánica de la SBS.

2 El sistema de la Reserva Federal fue creado en 1913 en respuesta al pánico bancario de 1907, primordialmente para aportar liquidez adicional en momentos de presión sobre los bancos. En 1930-33 el sistema no lo hizo, y no lo hizo pese al hecho de que había mucha gente dentro del sistema que le reclamaba que lo hiciera y que reconocía que ésta era su función correcta (Friedman 1992: 22).

3 Recibió el Premio Nobel de Economía en el año 2014 por su análisis del poder de los mercados y la regulación. Sus investigaciones se centran en los campos de organización industrial, banca y finanzas y economía y psicología.

4 Obra citada, página 504.

160/ QVIPURAMAYOC|Vol. 23(43) 2015 
Unidos (y la mayoría de los países) adoptaron una amplia gama de regulaciones bancarias en la forma de auditorías regulares de la Reserva Federal (Fed), seguro de depósitos, requerimientos de capital y requerimientos de reserva, y provisiones permitiendo que los bancos con problemas pidieran prestado en la ventanilla de descuento de la Fed.

En palabras de Stiglitzy Walsh (2009: 356), entre 1930 y 1933, Estados Unidos sufrió un masivo pánico financiero que supuso la quiebra de aproximadamente 9 mil oficinas bancarias. Este trastorno del sistema financiero contribuyó aún más la Gran Depresión, con unos niveles de desempleo que llegaron a representar hasta el $25 \%$ de la población activa.

Una solución al riesgo moral ${ }^{5}$ que existe en el sistema financiero ante una situación de pánico bancario, originado por los posibles retiros masivos de depósitos de las empresas del sistema financiero es el seguro de depósitos, denominado en algunos casos Fondo de Garantía de Depósitos (FGD) o Fondo de Seguro de Depósitos (FSD).

\section{Diagrama No 01:}

Seguro de depósitos: una solución al riesgo moral

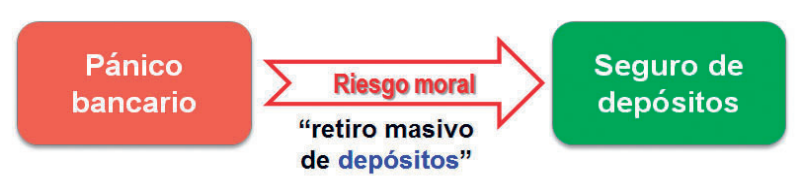

Fuente: Elaboración propia.
Krugman y Wells ${ }^{6}$ sostienen que casi todos los bancos en los Estados Unidos se anuncian como member of FDIC, la Federal Deposit Insurance Corporation. (...) la FDIC proporciona un seguro de depósitos, una garantía de que los depositantes recibirán su dinero incluso si el banco no puede reunir los fondos, hasta una cuantía máxima por cuenta. La FDIC garantiza los primeros US\$ 250 mil dólares por depositante, por cada banco asegurado. Es importante darse cuenta de que el seguro de depósitos no solo protege los depósitos si el banco realmente quiebra. El seguro también elimina la principal razón para las retiradas masivas: dado que los depositantes saben que sus fondos están seguros incluso si el banco quiebra, no tienen incentivo para apresurarse a retirarlos a causa de un rumor de que el banco pasa por dificultades.

En este contexto, Stiglitz y Walsh ${ }^{7}$ utilizan el concepto de equilibrio de Nash ${ }^{8}$ para explicar la relevancia de crear un FGD en el sistema financiero de un país, de tal manera que los depositantes de una empresa financiera no traten de retirar su dinero al mismo tiempo y en forma masiva. En ese sentido, utilizando la teoría de juegos ${ }^{9}$, analizan un caso sencillo de un banco con sólo dos depositantes: A y B; donde cada uno de los depositantes debe decidir entre dos opciones: 1) dejar su dinero en el banco, o 2 ) retirarlo.

Es así que en el siguiente diagrama se observa que existen dos equilibrios de Nash: 1) cuando ambos depositantes dejan su dinero; $y, 2$ ) cuando ambos depositantes retiran su dinero. Definitivamente, el mejor resultado para ambos es dejar el dinero en el banco antes que retirarlo.

$5 \mathrm{El}$ riesgo moral es una de las fallas que también se presenta en los mercados financieros. En general, existe riesgo moral cuando una de las partes de un acuerdo tiene un incentivo, después de logrado el acuerdo, para actuar de una manera que le produzca beneficios adicionales a costa de la otra parte.

6 Obra citada, página 420.

7 Obra citada, páginas 356-7.

8 Es la combinación de estrategias en un juego, tal que, ninguno de los dos jugadores tiene incentivo alguno para alterar la suya, dada la del adversario.

9 John Nash (1928) es un matemático estadounidense que formuló el concepto de equilibrio de la teoría de juegos en 1951. En tal sentido, se dice que un par de estrategias es un equilibrio de Nash si la elección del jugador X es óptima, dada la de Y.

La teoría de juegos se desarrolló con el objeto de analizar situaciones competitivas en las que intervienen intereses en conflicto. Fue inventada por John von Neumann en 1937 y ampliada por él mismo y Oskar Morgenstern en 1944. Dentro de esta categoría encajan las situaciones de duopolio, oligopolio, monopolio bilateral (un mercado con un solo vendedor y un solo comprador) y otras formas de rivalidades.

Un juego es una situación en la que los participantes toman decisiones estratégicas que tienen en cuenta las acciones y respuestas de los demás. El resultado final depende de lo que cada uno decida hacer. Por lo tanto, todos los juegos tiene tres elementos: 1) participantes, 2) estrategias, 3) ganancias. 


\section{Diagrama No 02:}

Pánico bancario como matriz de resultados de un juego estratégico ${ }^{10}$

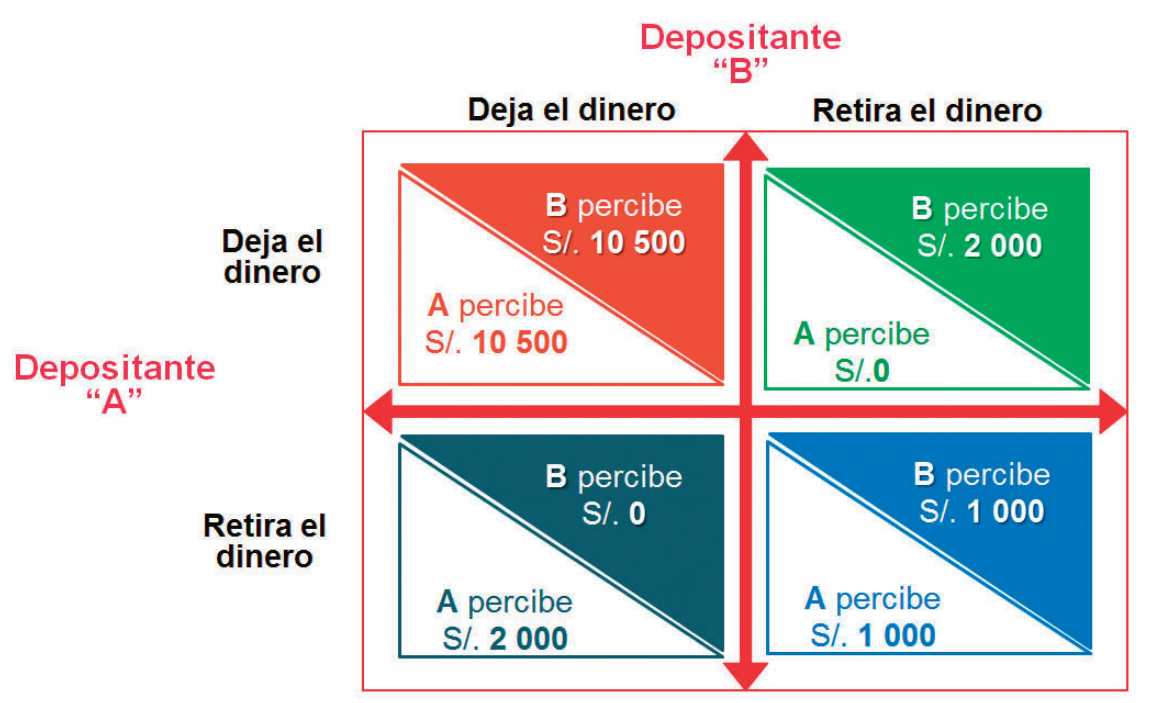

Fuente: Elaboración propia.

Dentro del marco establecido, supongamos que cada depositante ahorra S/. 10000 soles en un banco, y que dicha entidad, utiliza esos fondos para colocarlo en activos rentables (préstamos e inversiones), pero conserva S/. 2000 nuevos soles en su caja como reserva, considerando que la tasa de encaje es $10 \%$. Si los préstamos efectuados por el banco se devuelven, puede cumplir con pagar a sus depositantes una tasa de interés de $5 \%$ anual (rendimiento ofrecido al ahorrista).

Si ninguno de los depositantes retira sus fondos del banco hasta el plazo de vencimiento (un año), ambos percibirían luego de cumplirse el año, todo el valor de sus depósitos más el $5 \%$ de interés (un total de S/. 10500 nuevos soles). Si A retira su dinero del banco antes del vencimiento, mientras que B no lo hace, A sólo podrá retirar S/. 2000 nuevos soles (todo el efectivo que el banco tiene disponible en calidad de reservas). Luego, el banco tendrá que cerrar sus puertas, y B no percibiría dinero alguno.
Lo contrario ocurre si B trata de retirar sus fondos mientras que A no lo hace. Si ambos deciden retirar su dinero antes del vencimiento, lo máximo que cada uno podrá obtener sería S/. 1000 nuevos soles.

Es evidente que ambos depositantes salen ganando si ninguno retira sus fondos del banco antes del vencimiento. En este caso, ambos percibirían S/. 10500 nuevos soles. Se trata también de un equilibrio de Nash. Si A deja su dinero en el banco hasta el vencimiento, la mejor estrategia de B es hacer lo mismo. Inversamente, si B deja su dinero en el banco, la mejor estrategia de A es hacer lo mismo. Cada uno razona del siguiente modo: si el otro depositante deja su dinero en el banco, mi mejor estrategia es dejar también mi dinero. Por lo tanto, existe un equilibrio en el que ningún depositante trata de retirar sus fondos y el banco permanece abierto; generando así, una externalidad positiva porque beneficia a todo el sistema financiero en su conjunto ${ }^{11}$.

10 En los casos de interdependencia estratégica pueden estar involucrados muchos jugadores y muchas estrategias, pero nos limitaremos a analizar los juegos de dos personas que tienen un número finito de estrategias, lo que nos permitirá representarlos fácilmente en una matriz de resultados (Varian 2006: 523).

11 Como se analizará más adelante, el seguro de depósitos genera un incentivo para que los depositantes no retiren su dinero del banco, siendo por tanto, un ejemplo de externalidad positiva porque beneficia de una manera indivisible a toda una sociedad, independientemente de que las personas deseen o no, depositar su dinero en el sistema financiero. 
El segundo equilibrio de Nash se da cuando ambos depositantes retiran su dinero y el banco quiebra. En este caso, cada uno razona de la siguiente manera: si el otro depositante trata de retirar sus fondos antes del vencimiento, salgo ganando si también hago lo mismo. De este modo, al menos consigo S/. 1000 nuevos soles, que es mejor que nada. Así pues, existe un equilibrio en el que cada uno de ellos acude corriendo al banco, y éste es incapaz de cumplir plenamente sus obligaciones con los depositantes. En consecuencia, el banco quiebra.

Se trata pues, en buena cuenta, de una situación en la que puede haber un buen equilibrio (el banco continúa abierto y los depositantes al término de un período específico reciben todo su dinero depositado en el banco más los intereses pactados) y un mal equilibrio (el banco se ve obligado a cerrar).

Siendo así, se puede concebir el pánico financiero como el paso del buen equilibrio al mal equilibrio. Tal cosa podría suceder si los depositantes empezaran a preocuparse por la solidez financiera del sector bancario, aún en el caso de que tales temores fueran infundados. El sencillo argumento ilustrado con este juego proporciona una parte de la justificación de la garantía de depósitos bancarios. Con dicha garantía, cada depositante puede confiar en que su dinero está seguro independientemente de lo que hagan los demás depositantes, y ninguno de ellos tiene incentivo alguno para tratar de vencer a los demás retirando antes su dinero (Stiglitz y Walsh 2009: 358).

Por consiguiente, dado que existe un seguro de depósitos, cada depositante se ve incentivado o inducido a mantener su dinero en el banco en lugar de retirarlo. Esta situación se denomina efecto retención de los depósitos en el sistema financiero, lo cual definitivamente constituye una externalidad positiva para todos los depositantes, contribuyendo así a la mayor solidez y confianza del sistema financiero.

Debido a la existencia del riesgo moral, el Comité de Supervisión Bancaria de Basilea estableció expresamente, dentro de los Principios Básicos para sistemas de seguro de depósitos eficaces, lo siguiente:
Principio 2: Reducción del riesgo moral. Se debe reducir el riesgo moral cerciorándose de que el sistema de seguro de depósitos cuente con los elementos apropiados de diseño y a través de otros elementos de la red de seguridad del sistema financiero.

\section{IMPORTANCIA Y PROTECCIÓN DEL AHORRO PRIVADO}

El nivel de ahorro de un país constituye un elemento fundamental dentro de los mercados financieros para el desarrollo económico porque estos recursos terminan siendo canalizados hacia inversiones que incrementen la riqueza de una Nación ${ }^{12}$. Un mercado financiero competitivo y libre de trabas favorecerá el crecimiento del ahorro interno y propiciará su canalización, conjuntamente con el ahorro externo, hacia las actividades productivas. Por ello, es importante que los Estados fomenten y garanticen el ahorro de los agentes económicos.

Por ello, uno de los deberes primordiales del Estado peruano es promover el bienestar general que se fundamenta en la justicia y en el desarrollo equilibrado de la Nación (artículo 44 de la Constitución). En ese orden de ideas, el Estado fomenta y garantiza el ahorro privado, contemplado expresamente en el artículo $87^{\circ}$ de la Constitución:

El Estado fomenta y garantiza el ahorro. La ley establece las obligaciones y los límites de las empresas que reciben ahorros del público, así como el modo y los alcances de dicha garantía.

La banca es una actividad esencialmente inestable y por eso exige una regulación más intensa que cualquier otra actividad empresarial (Carbajales 2006: 43).

De esta forma, la regulación de las empresas del sistema financiero se justifica porque existe un interés económico-social general y por ello, un objetivo primordial que el Estado debe tutelar: garantizar el ahorro del público; ya que la actividad que realizan los bancos es bastante riesgosa, siendo el ahorro su principal fuente de financiamiento. Por esta razón, el Estado a través de una entidad supervisora regula y

12 Los mercados financieros están donde las familias invierten sus ahorros actuales y sus ahorros acumulados, es decir, su patrimonio o riqueza, comprando activos financieros (Krugman y Wells 2014: 291). 
supervisa el sistema financiero. Siendo así, el artículo $131^{\circ}$ de la Ley No 26702, Ley General del Sistema Financiero y del Sistema de Seguros y Orgánica de la Superintendencia de Banca y Seguros, establece que:

"El ahorro está constituido por el conjunto de las imposiciones de dinero ${ }^{13}$ que, bajo cualquier modalidad, realizan las personas naturales y jurídicas del país o del exterior, en las empresas del Sistema Financiero”.

De ahí que, el artículo $130^{\circ}$ de la Ley $N^{\circ} 26702$, dispone que con arreglo a la Constitución Política, el Estado promueve el ahorro bajo un régimen de libre competencia ${ }^{14}$.

A juicio del Tribunal Constitucional, a través del artículo $87^{\circ}$ de la Constitución, se ha reconocido el ahorro ${ }^{15}$ en cuanto derecho constitucional y como garantía institucional (EXP. N.o 0410-2002-AA/ TC. F.J. 2) ${ }^{16}$.

No obstante lo señalado en los párrafos precedentes, de acuerdo con Krugman y Wells ${ }^{17}$ en algunos países el nivel de ahorro es limitado debido a las siguientes razones:
1. El fácil acceso al crédito que tienen los consumidores en algunos países (por ejemplo, los prestamistas japoneses han requerido tradicionalmente grandes pagos iniciales a los compradores de viviendas). Por el contrario, hasta la reciente crisis inmobiliaria, era posible para los estadounidenses comprar viviendas con pagos iniciales pequeños o incluso sin ellos.

2. La provisión de una renta garantizada en la jubilación por el Sistema de la Seguridad Social, puede reducir el incentivo al ahorro privado.

\section{FONDO DE SEGURO DE DEPÓSITOS EN EL PERÚ ${ }^{18}$}

Es indudable que tras las crisis bancarias de los años 30, en muchos países del mundo se implementaron diversas medidas con la finalidad de proteger a los depositantes y a la economía en su conjunto contra las retiradas masivas. Se trata pues del seguro de depósitos, los requerimientos de capital, el encaje legal y los créditos de regulación monetaria.

\footnotetext{
13 Dinero es todo aquello que constituye un medio de cambio aceptable, utilizado de manera generalizada para la compra de bienes y/o servicios. Facilita el comercio o intercambio de bienes y/o servicios. Jorge Fernández (2008: 17) sostiene que el dinero no es sino un objeto digno de confianza, que todos los habitantes de una sociedad convienen en aceptar como una forma de riqueza almacenada, que sirve para facilitar las transacciones entre las personas. Todos pueden hacer sus pagos con estos objetos, y todos los aceptan como pago por la venta de cualquier bien o servicio.

14 "El concepto de libre competencia al que apunta la Constitución Política del Perú se adscribe al cuadro más amplio de la libertad económica. Como tal, supone dos aspectos esenciales:

a) La libertad de acceso al mercado por parte de los diversos agentes económicos. Quien tiene la capacidad de producir un bien o prestar un servicio, debe acceder al mercado en condiciones autodeterminativas, esto es, sin que nadie (ni el Estado ni el resto de agentes económicos) pueda impedir o restringir dicha participación.

b) La libertad de iniciativa o actuación dentro del mercado. Tras haberse accedido al mercado, se debe gozar de la suficiente capacidad de autodeterminación para competir conforme a las propias condiciones y variables económicas impuestas por la llamada ley de la oferta y la demanda." EXP. N. ${ }^{\circ}$ 3315-2004-AA/TC, F.J. 16.

15 Son depósitos de dinero a la vista efectuados en una cuenta abierta en una empresa del sistema financiero, a nombre de una persona denominada ahorrista. Estos depósitos pueden ser retirados por el ahorrista en cualquier momento. En: http://www.sbs.gob.pe/0/modulos/JER/JER_Interna.aspx?ARE=0\&PFL=1\&JER=1525.

16 En cuanto derecho subjetivo constitucional tiene, prima facie, una estructura semejante a lo que sucede con cualquier derecho de carácter reaccional: garantiza que el Estado no se apropie arbitrariamente del ahorro de los privados. Sin embargo, también participa de una faz positiva, por cuanto garantiza que el Estado realice todas aquellas medidas necesarias y acordes con los deberes de fomento y garantía del ahorro (...).

Y, como garantía institucional, esto es, en cuanto instituto constitucionalmente garantizado, impide que el Estado pueda legislativamente suprimirla o vaciarla de contenido. Tal garantía no sólo tiene una vertiente negativa, en el sentido de prohibir su supresión o vaciamiento de contenido, sino también una vertiente positiva, pues, como expresa la primera parte del artículo $87^{\circ}$ de la Constitución, impone al Estado el deber de fomentarla y garantizarla.

17 Obra citada, página 280.

18 http://www.fsd.org.pe/.
}

164/ QVIPURAMAYOC | Vol. 23(43) 2015 
Bajo tal premisa, en nuestro país existe un seguro de depósitos como mecanismo de protección del ahorro privado denominado Fondo de Seguro de Depósitos (FSD) ${ }^{19}$. Este seguro genera un efecto retención entre los depositantes de una empresa del sistema financiero, haciendo que éste sistema sea más sólido y confiable.

Con el propósito de comprender el funcionamiento del FSD en el Perú, a continuación se presentan los aspectos más importantes.

\section{Definición}

El FSD es una persona jurídica de derecho privado, de naturaleza especial, que tiene por objeto proteger a quienes realicen depósitos o imposiciones en las empresas del sistema financiero, con los alcances y limitaciones que establece la Ley No $26702^{20}$.

\section{Finalidad}

En la actualidad, el FSD tiene como finalidad velar por el mantenimiento de un sistema financiero sólido y confiable, a través de mecanismos modernos para la cobertura de depósitos asegurados y para la rehabilitación de empresas del sistema financiero que son miembros de éste.

\section{Miembros}

El FSD está integrado por las empresas de operaciones múltiple autorizadas a captar depósitos del público. En ese sentido, son miembros del FSD las empresas bancarias, financieras, cajas municipales de ahorro y crédito, cajas municipales de crédito popular y cajas rurales de ahorro y crédito (véase tabla).

Tabla No 01: Miembros del Fondo de Seguro de Depósitos (FSD)

\begin{tabular}{|c|c|c|c|c|}
\hline Bancos & Financieras & $\begin{array}{c}\text { Cajas } \\
\text { Municipales de } \\
\text { Ahorro y Crédito }\end{array}$ & $\begin{array}{c}\text { Cajas } \\
\text { Municipales de } \\
\text { Crédito Popular }\end{array}$ & $\begin{array}{l}\text { Cajas Rurales de } \\
\text { Ahorro y Crédito }\end{array}$ \\
\hline $\begin{array}{ll}\text { 1. } & \text { BBVA } \\
\text { 2. } & \text { Banco Azteca } \\
\text { 3. } & \text { Banco de Comercio } \\
\text { 4. } & \text { Banco de Crédito del } \\
& \text { Perú } \\
\text { 5. } & \text { Banco Financiero } \\
\text { 6. } & \text { Banco Ripley } \\
\text { 7. } & \text { Citibank } \\
\text { 8. } & \text { Deutsche Bank Perú } \\
\text { 9. } & \text { Falabella Perú } \\
\text { 10. } & \text { Banco GNB Perú } \\
\text { 11. Interamericano de } \\
\text { 12. Interbank } \\
\text { 13. MiBanco } \\
\text { 14. Santander Perú } \\
\text { 15. Scotiabank } \\
\text { 16. Banco Cencosud }\end{array}$ & $\begin{array}{ll}\text { 1. } & \text { CrediScotia } \\
\text { 2. } & \text { Confianza } \\
\text { 3. } & \text { Compartamos } \\
\text { 4. } & \text { Edyficar } \\
\text { 5. } & \text { TFC } \\
\text { 6. } & \text { Qapac } \\
\text { 7. } & \text { Amérika Financiera } \\
\text { 8. } & \text { Financiera } \\
\text { 9. } & \text { Proempresa } \\
\text { 9. } & \text { Financiera Efectiva }\end{array}$ & $\begin{array}{ll}\text { 1. } & \text { Arequipa } \\
\text { 2. } & \text { Cusco } \\
\text { 3. } & \text { Del Santa } \\
\text { 4. } & \text { Huancayo } \\
\text { 5. } & \text { Ica } \\
\text { 6. } & \text { Maynas } \\
\text { 7. } & \text { Paita } \\
\text { 8. } & \text { Piura } \\
\text { 9. } & \text { Sullana } \\
\text { 10. } & \text { Tacna Trujillo }\end{array}$ & $\begin{array}{l}\text { 1. Caja Municipal } \\
\text { de Crédito } \\
\text { Popular Lima }\end{array}$ & $\begin{array}{ll}\text { 1. } & \text { Cajamarca } \\
\text { 2. } & \text { Chavín } \\
\text { 3. } & \text { Credinka } \\
\text { 4. } & \text { Del Centro } \\
\text { 5. } & \text { Los Andes } \\
\text { 6. } & \text { Los Libertadores de } \\
& \text { Ayacucho } \\
\text { 7. } & \text { Prymera } \\
\text { 8. } & \text { Señor de Luren } \\
\text { 9. Señor de Sipan } \\
\text { 10. }\end{array}$ \\
\hline
\end{tabular}

Fuente: FSD

19 El FSD fue creado mediante la Ley General de Instituciones Bancarias, Financieras y de Seguros, aprobada en 1991 mediante Decreto Legislativo No 637. Desde el inicio, el FSD ha cumplido con el mandato legal de proteger el ahorro, cubriendo las cuentas de aquellas personas afectadas por los procesos de resolución de Peruinvest, Banco Popular, Banco Hipotecario, Caja Rurales de Ahorro y Crédito Valle del Río Apurímac y Ene, Selva Central, Majes, Banco República, Banco Banex, Banco Orión, Serbanco, Banco Nuevo Mundo, NBK Bank y Banco Latino.

Como consecuencia de las últimas modificaciones a la Ley No 26702 (vigente desde diciembre de 1996) se han producido cambios en la naturaleza del FSD. De este modo, ha asumido un rol más flexible, otorgándosele personería jurídica, así como, nuevas funciones y operaciones que le permitan cumplir cabalmente con sus objetivos.

20 La Ley No 26702 , a través de los artículos $144^{\circ}$ al $157^{\circ}$ regula todo lo referido al FSD. 
Por su parte, las entidades de desarrollo de la pequeña y micro empresa - EDPYMES - serán miembros del FSD cuando se les autoriza captar ahorros del público.

La categoría de miembro es intransferible e inherente a la empresa del sistema financiero autorizada a captar depósitos del público.

\section{Cobertura}

El FSD contempla un límite para la cobertura de cada depósito de ahorro en el sistema financiero. Bajo tal perspectiva, el monto máximo de cobertura para el período marzo - mayo 2015 es de S/. 93295 nuevos soles por persona en cada empresa miembro del FSD, comprendido los intereses. Este monto se va ajustando trimestralmente en función al Índice de Precios al Por Mayor (IPM) que publica el Instituto Nacional de Estadística e Informática (INEI) ${ }^{21}$.

El FSD actúa como mecanismo para contrarrestar posibles eventos de riesgos sistémicos. Por ello, percibe de todas las entidades captadoras de depósitos, una prima trimestral de acuerdo al nivel de riesgo al que este expuesta la entidad.

En este sentido, al cierre de setiembre del año 2014 el FSD tenía un fondo de S/.2 187 millones para asumir los pagos de posibles depositantes afectados. Estos fondos son invertidos bajo los criterios de seguridad, liquidez, rentabilidad y diversificación. Para ello, se tiene en cuenta la inversión preferente en: Moneda Extranjera, Obligaciones del Tesoro Público o BCR, Valores cuya adquisición este permitida para las AFP exceptuando a los emitidos por el Sistema Financiero y Fondos Mutuos cuyas inversiones se hayan efectuado dentro del país, estas inversiones deben ser clasificadas en categorías de riesgo I, II o equivalentes.

En el caso extremo que todas las instituciones financieras quebraran a la vez, el FSD tendría que pagar un monto de S/. 49034 millones a los depositantes, cuyos depósitos se encuentren por debajo del monto máximo de cobertura.

Tabla No 02: Cobertura del FSD en el sistema bancario peruano

\begin{tabular}{|l|r|r|}
\hline $\begin{array}{c}\text { Institución } \\
\text { Financiera }\end{array}$ & \multicolumn{1}{c|}{$\begin{array}{c}\mathbf{N}^{\circ} \text { de } \\
\text { depositantes }\end{array}$} & $\begin{array}{c}\text { Monto } \\
\text { (En miles S/.) }\end{array}$ \\
\hline Banca Múltiple & 14998146 & 39311504 \\
\hline Financieras & 997172 & 926581 \\
\hline CMAC & 2637240 & 7875824 \\
\hline CRAC & 169445 & 920530 \\
\hline Totales & $\mathbf{1 8 ~ 8 0 2 ~ 0 0 3}$ & $\mathbf{4 9 0 3 4 4 3 9}$ \\
\hline
\end{tabular}

Fuente: FSD y SBS

\section{Consejo de Administración}

El FSD cuenta con un Consejo de Administración y una Secretaría Técnica con las funciones y atribuciones establecidas en su estatuto. El Consejo de Administración está integrado por:

- Un representante de la Superintendencia de Banca, Seguros y AFP (SBS), designado por el Superintendente, quien lo preside.

- Un representante del Banco Central de Reserva del Perú, designado por su Directorio.

- Un representante del Ministerio de Economía y
Finanzas, designado por el Ministro.

- Tres representantes de las empresas del sistema financiero, designados por una Asamblea de Miembros.

\section{Instrumentos respaldados}

El FSD respalda únicamente los siguientes instrumentos:

a) Los depósitos nominativos, bajo cualquier modalidad, de las personas naturales y las personas jurídicas privadas sin fines de lucro;

$21 \mathrm{Al}$ inicio de sus operaciones (1991) el monto máximo de cobertura era S/. 2500 soles por persona.

166/ QVIPURAMAYOC|Vol. 23(43) 2015 
b) Los intereses devengados por los depósitos anteriormente mencionados, a partir de la fecha de constitución o de su última renovación; y

c) Los depósitos a la vista de las demás personas jurídicas, exceptuando los correspondientes a las empresas del sistema financiero.

Dicho monto incluye todos los depósitos asegurados que uno tiene en una misma entidad miembro del FSD. Los depósitos en diferentes agencias o sucursales de una misma empresa miembro no son asegurados independientemente.

Si se presentaran cuentas mancomunadas, el monto se distribuye en forma prorrateada entre los titulares de la cuenta y los límites aplican respecto de cada uno de ellos individualmente. El monto no cubierto por el FSD constituye crédito a ser tomado en cuenta para los fines de la liquidación y de acuerdo a las normas legales existentes.

\section{Casos atendidos}

Desde el inicio de las operaciones del FSD, se ha atendido a depositantes afectados de 13 entidades financieras por un monto desembolsado de aproximadamente $\mathrm{S} / .900$ millones, coberturando a más de 320 mil depositantes afectados.

Es importante mencionar, que el sistema financiero se vio afectado entre el período 1998-2001 por eventos externos como la crisis asiática ${ }^{22}$ (julio 1997) y la crisis rusa ${ }^{23}$ (agosto 1998), así como eventos internos como el Fenómeno del Niño de fuerte intensidad. Estos eventos contribuyeron en la caída de 6 bancos, por ello el FSD participó en el proceso de salida del mercado de estas entidades.

Para el caso, de los bancos NBK Bank, Banco Nuevo Mundo y Banco Latino el FSD no contaba con los recursos suficientes para atender a todos los depositantes afectados. Por ello, se solicitó al Tesoro Público un préstamo por el monto de US\$ 129 millones a un plazo de 10 años, a una tasa de interés Libor a $6 \mathrm{My}$ con pagos trimestrales.

Tabla No 03: Casos atendidos por el FSD

\begin{tabular}{|l|l|r|r|}
\hline \multicolumn{1}{|c|}{ Fecha } & \multicolumn{1}{|c|}{ Instituciones } & \multicolumn{1}{c|}{$\begin{array}{c}\text { No Depositantes } \\
\text { cubiertos }\end{array}$} & Monto (S/.) \\
\hline Abril 2001 & NBK Bank & 15214 & 148744975 \\
\hline Diciembre 2000 & Banco Nuevo Mundo & 23666 & 239176691 \\
\hline Noviembre 2000 & Banco Latino & n.d & 220591266 \\
\hline Setiembre 2000 & Banco Serbanco & 10500 & 79671031 \\
\hline Junio 2000 & Orión Corporación de Crédito Banco & 11105 & 47362218 \\
\hline Noviembre 1999 & BANEX & 14120 & 91267046 \\
\hline Setiembre 1999 & CRAC Selva Central & 977 & 1662277 \\
\hline Enero 1999 & CRAC Majes & 661 & 61479 \\
\hline Noviembre 1998 & Banco República & 30430 & 48492065 \\
\hline Abril 1997 & CRAC VRAE & 409 & 273825 \\
\hline Diciembre 1992 & Banco Popular & 51269 & 11193275 \\
\hline Agosto 1992 & Banco Hipotecario & 144184 & 34966489 \\
\hline Mayo 1992 & Financiera Peruinvest & 15847 & 4857774 \\
\hline
\end{tabular}

Fuente: FSD

22 La crisis asiática de julio 1997, afectó los precios internacionales trayendo como resultado que los exportadores vean reducidos sus ingresos.

23 La crisis rusa significó el cierre de líneas de crédito del exterior hacia los bancos locales reduciendo su liquidez para realizar sus operaciones. 


\section{Riesgo moral del seguro de depósitos}

De acuerdo con Stiglitz (2012: 229) los bancos habían demostrado la relevancia del riesgo moral, ya que los rescates habían provocado de forma reiterada y predecible una excesiva asunción de riesgos por parte de los bancos.

En esa línea, si bien un seguro de depósitos ha sido creado para lograr un efecto retención entre los depositantes del sistema financiero, también genera incentivos para que las empresas del sistema financiero realicen actividades más arriesgadas, debido a que dan por hecho que existe un seguro de protección del ahorro.

\section{CONCLUSIONES}

1. El fundamento para la creación de un seguro de depósitos es la eventual situación de pánico bancario, ocasionado por posibles retiros masivos de los fondos que los depositantes mantienen en las entidades financieras. En esa orientación, la importancia del seguro de depósitos genera un efecto retención entre los depositantes del sistema financiero. No obstante, si bien este seguro se constituye como un mecanismo de protección del ahorro privado ante retiradas masivas, en la práctica también incentiva a las empresas del sistema financiero a realizar operaciones más arriesgadas, como realizar préstamos dudosos a una tasa de interés alta. Por ello, el supervisor exige que los bancos mantengan más activos que el valor de los depósitos (requerimientos de capital), entre otras medidas.

2. El Estado peruano fomenta y garantiza el ahorro privado porque constituye un elemento fundamental para el desarrollo económico del país. De esta forma, la regulación de las empresas del sistema financiero se justifica porque existe un interés económico-social general y por ello, un objetivo primordial que el Estado debe tutelar: garantizar el ahorro del público; ya que la actividad que realizan los bancos es bastante riesgosa, siendo el ahorro su principal fuente de financiamiento.
3. El FSD tiene como principal objetivo proteger a los depositantes de las entidades financieras, en caso tales entidades, miembros del FSD donde los clientes mantienen sus depósitos, quiebren. Así, en caso de quiebra de una entidad financiera, el FSD devuelve a los depositantes por concepto de depósito, más intereses generados hasta por el monto máximo de cobertura vigente, que para el período marzo - mayo 2015 es de S/.93295 nuevos soles por persona en cada empresa miembro del FSD, comprendido los intereses.

4. El Fondo respalda únicamente los depósitos nominativos de las modalidades a la vista, ahorro y a plazo, de personas naturales y personas jurídicas privadas sin fines de lucro, así como los depósitos a la vista de las demás personas jurídicas. Asimismo, la cobertura es por persona y por institución.

\section{REFERENCIAS BIBLIOGRÁFICAS}

1. CARBAJALES, Mariano (2006) La Regulación del Mercado Financiero. Madrid. Editorial Marcial Pons.

2. FERNÁNDEZ, Jorge (2008) Teoría y Política Monetaria. Lima. Universidad del Pacífico.

3. FRIEDMAN, Milton (1992) La Economía Monetarista. Barcelona. Editorial Gedisa S.A.

4. KRUGMAN, Paul - WELLS Robin (2014) Macroeconomía. Tercera edición. Barcelona. Editorial Reverté S.A.

5. Ley No 26702, Ley General del Sistema Financiero y del Sistema de Seguros y Orgánica de la Superintendencia de Banca y Seguros.

6. STIGLITZ, Joseph E. (2012) El precio de la desigualdad. México. Editorial Taurus.

7. (2009) Microeconomía. Cuarta edición. Madrid. Editorial Ariel S.A.

8. TRIBUNAL CONSTITUCIONAL (2004) EXP. N.o 3315-2004-AA/TC

9. (2002) EXP. N.o 0410-2002-AA/TC

10.VARIAN, Hal (2006) Microeconomía Intermedia. Séptima edición. España. Antoni Bosch, editor S.A. 


\section{REFERENCIAS ELECTRÓNICAS}

1. Fondo de Seguro de Depósitos: http://www.fsd. org.pe/

2. Superintendencia de Banca, Seguros y AFP: http://www.sbs.gob.pe/ 